\title{
Modeling Start Curves of Bainite Formation
}

\author{
S.M.C. VAN BOHEMEN
}

It is demonstrated that calculations with a physically based model give an accurate description of the start curve of bainite formation in a wide range of steels. The temperature dependence of the overall kinetics, which determines the characteristic $\mathrm{C}$ shape of the start curve, is controlled by both the undercooling below the start temperature $\left(T_{h}-T\right)$ and an effective activation energy $Q_{b}$. A systematic analysis of the model parameters extracted from the best fits of published time-temperature-transformation (TTT) data reveals a material-independent relationship, which means that the activation energy is in accordance with known details of the dislocationbased nucleation model of bainite. It is shown that the $\mathrm{C}$ shape of the start curve can be determined for a given alloying content using an empirical relationship derived for $Q_{b}$ and, in combination with the material-independent relationship, the kinetics of bainite can be predicted at all temperature levels.

DOI: $10.1007 / \mathrm{s} 11661-009-0106-9$

(C) The Author(s) 2009. This article is published with open access at Springerlink.com

\section{INTRODUCTION}

OvER the last 80 years, much experimental work has been conducted to construct time-temperature-transformation (TTT) diagrams of various steels. ${ }^{[1-5]}$ These diagrams display the initiation of the various possible transformations and typically consist of two C-shaped start curves, which are separated by a region that is called the bay. The $\mathrm{C}$ curve at relatively high temperatures describes the progress of diffusional transformation microstructural constituents such as ferrite and pearlite, whereas the $\mathrm{C}$ curve below the bay corresponds to displacive transformations such as bainite and Widmanstätten ferrite. ${ }^{[6,7]}$ The exact shape and position of the curves constituting the TTT diagram are dependent on the composition and grain size of the austenite that transforms. By the addition of certain alloying elements, e.g., Mo or $\mathrm{Cr}$, the bay region becomes wider, while in plain carbon steels, the decomposition of austenite to ferrite is so rapid that the two transformation ranges overlap to such an extent that there appears to be only a single $\mathrm{C}$ curve in the TTT diagrams, which is the combined result of diffusional and displacive transformations. ${ }^{[5-7]}$

The existing physically based models for bainite formation can be divided into two categories, namely displacive and diffusional models. The controversy between the two transformation mechanisms is an ongoing debate in literature. ${ }^{[8-11]}$ Although diffusional models implicitly predict C-curve kinetics of bainite in accordance with experimental observations, many model parameters have to be chosen in the calculations,

S.M.C. VAN BOHEMEN, Researcher, formerly with the Department of Materials Science and Engineering, Delft University of Technology, Mekelweg 2, 2628 CD Delft, The Netherlands, is with Corus RD\&T, 1970 CA IJmuiden, The Netherlands. Contact e-mail: s.m.c.vanbohemen@gmail.com

Manuscript submitted July 30, 2009

Article published online December 2, 2009 including an arbitrary incubation time. ${ }^{[12]}$ On the other hand, kinetic simulations based on Bhadeshia's displacive transformation model predict a bainite start curve with a flat top. ${ }^{[6,7]}$ This is related to the assumption that the number density of potential nucleation sites is constant. ${ }^{[13]}$ In contrast, by assuming the density of potential nucleation sites to be proportional with the driving force, a displacive model was recently developed that predicts a C-shaped start curve. ${ }^{[14]}$ Furthermore, this proposed expression for bainite formation contains only two well-defined adjustable parameters. ${ }^{[14]}$

The primary objective of the present study is to understand and predict the characteristic $\mathrm{C}$ shape of the start curve of bainite, as observed in TTT diagrams of various steels. The analytical expression for isothermal bainite formation proposed in Reference 14 is the starting point in this investigation. An expression for the time required to form a certain fraction bainite at various temperatures will be derived and calculations are compared to the experimental start curves of steels with a wide range of compositions. It will be shown that the model accurately describes the transformation kinetics over the whole temperature range, including the nose region. The correct model prediction of the $\mathrm{C}$ shape of the start curve was already conjectured in Reference 15; however, confirmation was not possible in either Reference 14 or Reference 15 , because the plain carbon steels that were investigated do not display a nose in the TTT diagram.

In the present work, a thorough validation of the model is accomplished using 40 published TTT diagrams. The accurate description of start curves engenders confidence in the transformation model and gives indirect evidence that the displacive growth mechanism is a plausible assumption. The parameters extracted from the best fits are systematically analyzed, and it will be shown that the characteristic $\mathrm{C}$ shape of each investigated start curve is governed by an effective activation energy for which an empirical formula is developed. Furthermore, there appears to be a material-independent 
relationship between the temperature-independent rate factor and the effective activation energy. These findings permit us to make predictions of the start curves for various steel compositions. The proposed methodology for the calculation of start curves can aid in our understanding of bainite kinetics in general, and can also be of practical importance in the thermomechanical processing of steels and the development of new alloys.

\section{THEORY}

\section{A. Transformation Model}

In a previous article by the present author, ${ }^{[14]}$ a transformation model describing the fraction bainite $f$ as a function of time was developed on the basis of the assumed displacive growth of bainite in combination with the nucleation rate, similar to other investigations, ${ }^{[13,16,17]}$ expressed as ${ }^{[14]}$

$$
\frac{d N}{d t}=v(1-f) N_{i}(1+\lambda f) \exp \left(-\frac{Q^{*}}{\mathrm{R} T}\right)
$$

where $v$ is the attempt frequency, which is assumed constant and is chosen as $1 \times 10^{13} \mathrm{~s}^{-1[16]}$ in all calculations. The nucleation rate of bainite depends on $N_{i}$, the number density of potential nucleation sites initially present in the austenite, and the activation energy $Q^{*}$. The contribution from autocatalytic nucleation is incorporated by the factor $(1+\lambda f) \cdot{ }^{[13,17,18]}$ Different from other models, it was assumed in Reference 14 that $N_{i}$ depends linearly on the net driving force at $T$, and is thus proportional to $\left(T_{h}-T\right)$. The temperature $T_{h}$ is the highest temperature at which a displacive transformation can occur, ${ }^{[19]}$ and this temperature corresponds to the start temperature for either Widmanstätten ferrite or bainite. Based on these assumptions and Eq. [1], it was derived that the fraction bainite $f$ can be calculated as a function of time with ${ }^{[14]}$

$$
f=\frac{1-\exp (-\kappa(1+\lambda) t)}{\lambda \exp (-\kappa(1+\lambda) t)+1}
$$

in which $\kappa$ is a temperature-dependent rate constant defined by

$$
\kappa=v \alpha_{b}\left(T_{h}-T\right) \exp \left(-\frac{Q^{*}}{\mathrm{R} T}\right)
$$

where $\alpha_{b}$ is a constant that is inversely proportional to the austenite grain diameter $d^{\prime} \cdot{ }^{[14,18]}$ The constant $\alpha_{b}$ is directly related to $N_{i}$ and represents the effectiveness of austenite grain boundaries for the nucleation of bainite. Based on the derivation given in Reference $14, \alpha_{b}$ is calculated as

$$
\alpha_{b}=\frac{Z \delta}{d \gamma} \alpha_{m}
$$

where $\delta$ is the effective thickness of the austenite grain boundary, $Z$ is a geometrical factor, and $\alpha_{m}$ is a kinetic parameter describing the rate of martensite formation in the alloy. ${ }^{[1,20-22]}$ In the present study, $\alpha_{b}$ is calculated for each alloy using Eq. [4] with the constants $Z=6, \delta=1 \mathrm{~nm}$, and $\alpha_{m}=0.015 \mathrm{~K}^{-1}$; thus, $\alpha_{b}=$ $\left(9 \times 10^{-5} \mu \mathrm{mK}^{-1}\right) / d^{\prime}$.

In References 14 and 15, it was demonstrated for several plain carbon steels that the bainite formation as a function of time at various temperatures can be described using a single autocatalytic parameter $\lambda$ and a temperature-dependent rate parameter $\kappa$. Evaluation of the model parameters in Reference 14 using Eq. [3] showed that $Q^{*}$ decreases linearly with decreasing temperature and can be described by

$$
Q^{*}=Q_{0}-K_{1} \Delta G_{m}
$$

in which $Q_{0}$ is a constant, $K_{1}$ is a constant of proportionality, and $\Delta G_{m}$ is the maximum driving force. Calculations for various steel compositions have shown that in the temperature range of bainite formation, the slope $\Gamma=d\left(\Delta G_{m}\right) / d T$ is constant, which is in agreement with the results reported in References 17 and 19. Therefore, the maximum driving force can be expressed as $\Delta G_{m}=\Gamma\left(T_{1}-T\right)$, with $T_{1}$ a temperature found by extrapolation of the linear dependence to $\Delta G_{m}=0$.

The obtained linear dependence of $Q^{*}$ on the driving force in Reference 14 engendered confidence in the modeling approach, because this relationship is in qualitative agreement with the dislocation-based nucleation model of bainite, ${ }^{[9]}$ which was derived by Bhadeshia using the isothermal martensite nucleation theory proposed by Olson and Cohen. ${ }^{[23]}$ This nucleation model will be discussed in more detail in the discussion of the results, in which it will be shown that an evaluation of the model parameters in the present study leads to a very similar expression of $Q^{*}$, as proposed in Reference 9.

\section{B. Transformation Start Curve}

In order to validate the transformation model using the published experimental start curves of bainite, the inverse function of Eq. [2] is determined. At a given temperature, the time $t$ required to form a volume fraction bainite $f$ can be calculated as

$$
t=\frac{-\ln \left(\frac{1-f}{1+\lambda f}\right)}{\kappa(1+\lambda)}
$$

Because $\lambda$ is not dependent on the isothermal holding temperature and constant for a specific austenitizing temperature $T_{\text {aus }}{ }^{[14]}$ the distinct $\mathrm{C}$ shape of the start curve is determined by the temperature dependence of $\kappa$. To explicitly show which parameters control the temperature dependence of $\kappa$, Eq. [3], in combination with $\Delta G_{m}=\Gamma\left(T_{1}-T\right)$ and Eq. [5], is rewritten as

$$
\kappa=v B\left(T_{h}-T\right) \exp \left(-\frac{Q_{b}}{\mathrm{R} T}\right)
$$

with

$$
Q_{b}=Q_{0}-K_{1} \Gamma T_{1}
$$


which is denoted as the effective activation energy for bainite formation, and the pre-exponential factor $B$ is described by

$$
B=\alpha_{b} \exp \left(-\frac{K_{1} \Gamma}{\mathrm{R}}\right)
$$

With this expression of $\kappa$ shown in Eq. [7], it is readily understood that the typical shape of the start curve is governed by both $Q_{b}$ and $\left(T_{h}-T\right)$. The pre-exponential factor $B$ determines the overall (temperature-independent) rate of the transformation, i.e., this parameter shifts the start curve in the $t$ direction of the TTT diagram. Figure 1 illustrates qualitatively how the parameters $B$ and $Q_{b}$ change the transformation start curve. For temperatures below the nose of the start curve, the increase in start time with decreasing temperature becomes stronger when $Q_{b}$ increases. Furthermore, the relative location of the additional curves corresponding to later stages of transformation is controlled by the autocatalytic parameter $\lambda$, which will be explained in more detail later.

From Eq. [6], it is evident that the nose of the C-shaped start curve is simply determined by the maximum in the rate parameter $\kappa$. When $\kappa$ (Eq. [7]) is differentiated with respect to $T$, the temperature corresponding to the nose of the C curve in the TTT diagram, $T_{\text {nose }}$, can be evaluated as

$$
T_{\text {nose }}=-\frac{Q_{b}}{2 \mathrm{R}}+\frac{1}{2} \sqrt{\left(\frac{Q_{b}}{\mathrm{R}}\right)^{2}+4 \frac{Q_{b}}{\mathrm{R}} T_{h}}
$$

Calculations show that for decreasing $Q_{b}$, the difference between $T_{h}$ and $T_{\text {nose }}$ increases.

\section{Modeling Approach}

In the present study, many published TTT diagrams of various steels are analyzed to compare the start

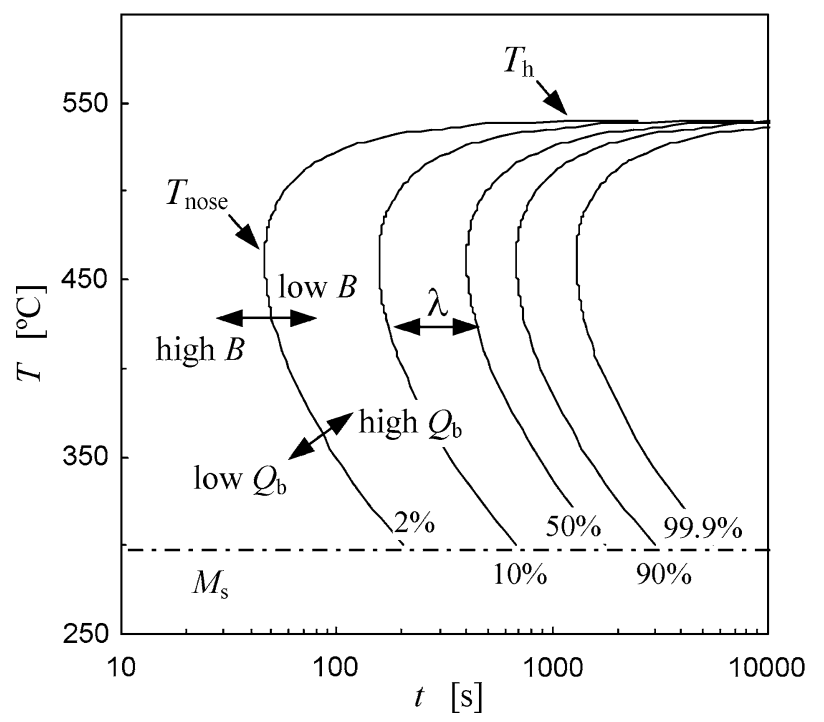

Fig. 1-TTT diagram showing the effect of $B$ and $Q_{b}$ on the transformation start curve. curves with calculations using Eq. [6]. The agreement between the calculated and experimental start curves is optimized by adjusting $Q_{b}$ and $B$. In the discussion of the results, the model parameters $Q_{b}$ and $B$ extracted from the best fits will be systematically analyzed and interpreted in terms of associated parameters.

The parameters $\lambda$ and $T_{h}$ are also evaluated from the experimental data, and some additional remarks are given on the determination of these parameters. Most of the steels studied contain significant additions of $\mathrm{Cr}$ or Mo, which means that the bay region is wide and, consequently, $T_{h}$ is strictly defined by the experimental start curve. For only a few of the TTT diagrams studied is this not the case because of overlap with the pearlite/ ferrite start curve or due to insufficient experimental data in the temperature regime of the bay. The autocatalytic parameter $\lambda$ determines the $\mathrm{S}$ shape of the fraction-time curve. ${ }^{[13,14]}$ This means that $\lambda$ is related to the difference in time between the start curve and the additional curves in the TTT diagram. In the present investigation, $\lambda$ is determined by optimizing the overall agreement with the experimental start, halfway, and finish curves. In Reference 14, it was demonstrated that $\lambda$ increases with increasing austenite grain size $d^{\prime}$, and other studies indicated that $\lambda$ is also dependent on the chemical composition of the steel. ${ }^{[13,24]}$ However, the precise mechanism of autocatalytic nucleation is not thoroughly established and further research is required to get a quantitative understanding of the influence of alloying elements and carbide formation on $\lambda$. When only the start curve is given in an analyzed TTT diagram, a best estimate of $\lambda$ is determined on the basis of the reported $d^{\prime}$ or $T_{\text {aus }}$ and qualitative knowledge of the variation in $\lambda$ with composition. An assessment of possible inaccuracies in $\lambda$ will be given.

\section{DATA FROM THE LITERATURE}

Forty published TTT diagrams have been analyzed in order to validate the transformation model. The alloys investigated comprise a wide range of chemical compositions, as seen in Table I. For most of the alloys, the austenitizing temperature $T_{\text {aus }}$ and the ASTM austenite grain size number $N$ have been reported (Table I). The corresponding grain diameter $d$ is calculated using $d^{\prime}=\sqrt{(100 \times 25.4 \times 25.4) /\left(2^{N-1}\right)} \mu \mathrm{m}$.

According to the literature, ${ }^{[5]}$ the most commonly used method of obtaining the data for TTT diagrams is the microscopic method originally used by Davenport and Bain. ${ }^{[25]}$ This method was probably employed for most of the steels examined in the present investigation. The analyzed TTT diagrams originate from different sources in literature ${ }^{[1-5]}$ and have been developed in various nations. In each TTT diagram, it is often not clearly stated which fraction of bainite $f_{\text {start }}$ served to construct the experimental start curve. The smallest fraction detectable in optical micrographs is assumed to be in the range of 0.5 to 4 vol pct. For each alloy analyzed in the present investigation, the option of associating the experimental start curve with 2 vol pct transformation was chosen. 


\begin{tabular}{|c|c|c|c|c|c|c|c|c|c|c|c|c|}
\hline \multirow[b]{2}{*}{ Sample } & \multirow[b]{2}{*}{ Steel Code } & \multirow[b]{2}{*}{ Reference } & \multirow[b]{2}{*}{$\mathrm{C}$} & \multirow[b]{2}{*}{$\mathrm{Mn}$} & \multirow[b]{2}{*}{$\mathrm{Si}$} & \multirow[b]{2}{*}{$\mathrm{Cr}$} & \multirow[b]{2}{*}{$\mathrm{Ni}$} & \multirow[b]{2}{*}{ Mo } & \multicolumn{3}{|c|}{ From Literature } & \multirow{2}{*}{$\begin{array}{c}\text { Eq. }[10 \\
T_{\text {nose }}\end{array}$} \\
\hline & & & & & & & & & $T_{\text {aus }}$ & $N$ & $T_{\text {nose }}$ & \\
\hline 1 & $\mathrm{Fe}-0.15 \mathrm{C}-3 \mathrm{Cr}$ & 4, p. 205 & 0.15 & 0.24 & 0.12 & 2.90 & - & - & - & - & 500 & 463 \\
\hline 2 & $\mathrm{Fe}-0.26 \mathrm{C}-3 \mathrm{Cr}$ & 4, p. 207 & 0.26 & 0.31 & 0.23 & 3.11 & - & - & - & & 420 & 405 \\
\hline 3 & $\mathrm{Fe}-0.15 \mathrm{C}$ & 4, p. 227 & 0.15 & 0.45 & 0.20 & 1.54 & 4.03 & 0.03 & - & 7 to 9 & 400 & 370 \\
\hline 4 & $\mathrm{Fe}-0.29 \mathrm{C}-7 \mathrm{Ni}$ & 1, p. 153 & 0.29 & 0.15 & 0.13 & 0.04 & 7.60 & 0.01 & - & - & 500 & 451 \\
\hline 5 & $\mathrm{Fe}-0.12 \mathrm{C}$ & 1, p. 523 & 0.12 & 0.85 & 0.24 & 0.54 & 1.05 & 0.51 & 1200 & - & 490 & 448 \\
\hline 6 & SAE 4150 & 2, p. 141 & 0.50 & 0.80 & 0.32 & 1.04 & 0.11 & 0.24 & 850 & 7 to 8 & 470 & 458 \\
\hline 7 & SAE 4330 & 1, p. 327 & 0.30 & 0.69 & 0.22 & 0.85 & 2.83 & 0.30 & 1095 & 1 to 3 & 440 & 430 \\
\hline 8 & $\mathrm{Fe}-0.27 \mathrm{C}$ & 1, p. 333 & 0.27 & 0.53 & 0.26 & 0.71 & 3.38 & 0.18 & 1000 & - & 430 & 431 \\
\hline 9 & $\mathrm{Fe}-0.29 \mathrm{C}-\mathrm{Mo}$ & 4, p. 52 & 0.29 & 1.64 & 0.24 & 0.05 & 0.02 & 0.45 & - & 7 to 8 & 500 & 491 \\
\hline 10 & $\mathrm{Fe}-0.38 \mathrm{C}-3 \mathrm{Cr}$ & 1, p. 53 & 0.38 & 0.20 & 0.18 & 2.98 & - & - & 1200 & 2 to 3 & 440 & 416 \\
\hline 11 & $\mathrm{Fe}-0.42 \mathrm{C}-1 \mathrm{Cr}$ & 1, p. 177 & 0.42 & 0.72 & - & 0.99 & 0.05 & 0.42 & 1100 & 3 to 4 & 490 & 480 \\
\hline 12 & En 25 & 1, p. 100 & 0.31 & 0.62 & - & 0.64 & 2.63 & 0.58 & 835 & 6 to 7 & 420 & 413 \\
\hline 13 & En23 & 1, p. 100 & 0.32 & 0.61 & 0.28 & 0.63 & 3.22 & 0.22 & 830 & 7 & 450 & 457 \\
\hline 14 & En24 & 1, p. 101 & 0.38 & 0.69 & 0.20 & 0.95 & 1.58 & 0.26 & 835 & 7 to 8 & 450 & 449 \\
\hline 15 & En100 & 1, p. 101 & 0.40 & 1.34 & 0.21 & 0.53 & 1.03 & 0.22 & 845 & 6 & 460 & 462 \\
\hline 16 & En110 & 5, p. 100 & 0.39 & 0.62 & 0.23 & 1.11 & 1.44 & 0.18 & 845 & 7 to 8 & 455 & 460 \\
\hline 17 & En36 & 5, p. 106 & 0.70 & 0.35 & 0.16 & 0.96 & 3.24 & 0.06 & 860 & $>8$ & 380 & 407 \\
\hline 18 & En 11 & 5, p. 96 & 0.59 & 0.66 & 0.34 & 0.65 & 0.17 & 0.02 & 840 & 8 & 495 & 508 \\
\hline 19 & En17 & 5, p. 97 & 0.38 & 1.49 & 0.25 & 0.14 & 0.24 & 0.41 & 845 & 8 & 465 & 469 \\
\hline 20 & En18 & 5, p. 96 & 0.48 & 0.86 & 0.25 & 0.98 & 0.18 & 0.04 & 860 & 5 to 6 & 485 & 490 \\
\hline 21 & NE 8949 & 1, p. 350 & 0.52 & 1.19 & - & 0.51 & 0.53 & 0.35 & - & 7 to 8 & 465 & 477 \\
\hline 22 & NE 9540 & 1, p. 373 & 0.38 & 1.45 & 0.66 & 0.52 & 0.57 & 0.19 & - & 10 to 11 & 490 & 458 \\
\hline 23 & $3310(0.6$ pct $C)$ & 5, p. 33 & 0.60 & 0.45 & - & 1.52 & 3.33 & - & 927 & 6 & 400 & 401 \\
\hline 24 & $3310(0.8$ pct $C)$ & 5, p. 33 & 0.80 & 0.45 & - & 1.52 & 3.33 & - & 927 & 8 & 385 & 375 \\
\hline 25 & $\mathrm{Fe}-0.39 \mathrm{C}-\mathrm{Mo}$ & 4, p. 55 & 0.39 & 1.58 & 0.27 & 0.16 & 0.05 & 0.44 & - & 8 to 9 & 480 & 452 \\
\hline 26 & $\mathrm{Fe}-0.39 \mathrm{C}-\mathrm{Ni}-\mathrm{Mo}$ & 1, p. 461 & 0.39 & 0.56 & - & - & 3.53 & 0.74 & 870 & 8 to 9 & 460 & 470 \\
\hline 27 & $\mathrm{Fe}-0.51 \mathrm{C}$ & 4, p. 184 & 0.51 & 0.73 & - & 0.99 & 2.74 & 0.45 & 920 & - & 410 & 408 \\
\hline 28 & $\mathrm{Fe}-0.55 \mathrm{C}$ & 4, p. 185 & 0.55 & 0.60 & & 1.03 & 0.36 & 0.19 & 920 & 7 to 8 & 470 & 469 \\
\hline 29 & $\mathrm{Fe}-0.72 \mathrm{C}-\mathrm{Mo}$ & 1, p. 121 & 0.72 & 0.32 & 0.19 & 0.09 & 0.09 & 0.45 & - & 7 to 8 & 535 & 540 \\
\hline 30 & $\mathrm{Fe}-0.52 \mathrm{C}-\mathrm{Mn}$ & 1, p. 202 & 0.52 & 1.18 & 0.30 & 0.13 & 0.16 & 0.30 & - & 8 to 9 & 505 & 512 \\
\hline 31 & $\mathrm{Fe}-0.80 \mathrm{C}-\mathrm{Mo}$ & 1, p. 120 & 0.80 & 0.90 & 0.30 & 0.09 & 0.16 & 0.44 & - & 8 to 9 & 465 & 483 \\
\hline 32 & $\mathrm{Fe}-0.77 \mathrm{C}-\mathrm{Mo}$ & 1, p. 124 & 0.77 & 0.72 & 0.20 & - & - & 0.72 & 850 & 8 & 520 & 524 \\
\hline 33 & Fe-0.79C-Mo & 1, p. 130 & 0.79 & 0.76 & 0.27 & - & - & 0.77 & 850 & 8 & 495 & 497 \\
\hline 34 & $\mathrm{Fe}-0.97 \mathrm{C}$ & 1, p. 312 & 0.97 & 0.72 & 0.32 & 0.80 & 1.54 & 0.26 & - & 2 to 4 & 420 & 423 \\
\hline 35 & $\mathrm{Fe}-1.04 \mathrm{C}-4 \mathrm{Cr}$ & 1, p. 58 & 1.04 & 0.18 & 0.35 & 4.00 & - & & - & 2 & 340 & 351 \\
\hline 36 & $\mathrm{Fe}-0.98 \mathrm{C}-\mathrm{Mn}-\mathrm{Si}$ & 31 & 0.98 & 1.89 & 1.46 & 1.26 & - & 0.26 & - & - & - & - \\
\hline 37 & $\mathrm{Fe}-0.8 \mathrm{C}-2 \mathrm{Mn}$ & 1, p. 92 & 0.80 & 1.88 & - & - & - & - & 950 & 5 to 8 & - & - \\
\hline 38 & $\mathrm{Fe}-1.2 \mathrm{C}-2 \mathrm{Mn}$ & 1, p. 93 & 1.20 & 1.88 & - & - & - & - & 950 & 6 to 8 & - & - \\
\hline 39 & $\mathrm{Fe}-0.79 \mathrm{C}-5 \mathrm{Ni}$ & 1, p. 147 & 0.79 & 0.23 & 0.22 & 0.04 & 5.25 & 0.01 & - & - & - & - \\
\hline 40 & $\mathrm{Fe}-0.80 \mathrm{C}-5 \mathrm{Ni}$ & 1, p. 145 & 0.80 & 0.52 & 0.28 & 0.07 & 5.00 & 0.03 & - & 6 & - & - \\
\hline
\end{tabular}

It is noted that deviations from this assumed fraction of $2 \mathrm{vol}$ pct cause an inaccuracy in the temperatureindependent rate factor $B$ derived by fitting to the published TTT data. This uncertainty in $f_{\text {start }}$ will be assessed and accounted for in the discussion of the model parameters. To give a rough estimate of this inaccuracy, when the actual start curve corresponds to $f_{\text {start }}=1 \mathrm{vol}$ pct, the value of $B$ extracted from the best fit is approximately 40 pct smaller than the value of $B$ evaluated for the assumed fraction of 2 vol pct. The temperature-independent rate factor $B$ is also correlated with $\lambda$, which is for some steels not accurately determined because of insufficient experimental data. However, $B$ is influenced only moderately by changing $\lambda$. The inaccuracy in $B$ due to uncertainties in $\lambda$ is approximately 15 pct, which is relatively small as compared to the influence of uncertainties in $f_{\text {start }}$ on $B$.
In most of the published TTT diagrams, the experimental data points are not plotted. Only a curve, the best fit based on a limited set of precise measurements and empirical knowledge of the characteristic $\mathrm{C}$ shape, ${ }^{[5]}$ is shown. However, for a few alloys, more detailed TTT diagrams, including the underlying data, have been reported, e.g., Reference 26, and analysis of these data discussed in Section IV gives insight into the experimental inaccuracies involved in the construction of TTT diagrams. The experimental inaccuracy is also apparent from the significant differences that can be identified between TTT diagrams of different steel codes with virtually the same composition, which has also been mentioned by Lee and Bhadeshia. ${ }^{[7]}$ This information will be used to give a well-balanced assessment of the accuracy that can be attained with the simulations. 


\section{RESULTS}

On the basis of the proposed transformation model (Eq. [6]), the start curves of bainite have been calculated for all the alloys listed in Table I. The values of $\lambda, T_{h}$, $Q_{b}$, and $B$ used in the calculations to optimize the agreement with the experimental data are shown in Table II. The values of $T_{\text {nose }}$ calculated with Eq. [10] are listed in Table I, for comparison with values determined from the experimental start curves. Comparison of these $T_{\text {nose }}$ values gives a qualitative indication of the agreement between the calculated and experimental start curve in the region near the nose of the $\mathrm{C}$ curve.

Figure 2(a) shows that for steel En $24,{ }^{[1]}$ the start curve of bainite is very well described by the transformation model. In the low-temperature range of $300{ }^{\circ} \mathrm{C}$ to $400{ }^{\circ} \mathrm{C}$, the calculated $10,50,90$, and 99.99 pct curves differ somewhat from the experimental curves. The best fit would be obtained for calculated 7, 34, 95, and
99.998 pct curves. To a considerable extent, these small differences can be explained by experimental uncertainties, because similar discrepancies are sometimes observed by comparing TTT diagrams of the same steel code published in different literature sources. In the upper part of the temperature range of bainite formation (above approximately $400{ }^{\circ} \mathrm{C}$ for En 24), the transformation is very slow and incomplete, according to the experimental curves. In the literature, this phenomenon has been reported for many experimental data; ${ }^{[7,27,28]}$ however, no conclusive explanation has been given as to the reason the transformation to bainite in the high temperature range is incomplete in such steels with a low $\mathrm{Si}$ and $\mathrm{Al}$ content. Based on its morphology, the bainite formed in this temperature range is sometimes called granular bainite. ${ }^{[29,30]}$ In the comprehensive article by Steven and Haynes ${ }^{[27]}$ in which they investigated many British Standards (B.S.) En

Table II. Overview of Parameters Used in Model Calculations

\begin{tabular}{|c|c|c|c|c|c|c|c|c|c|}
\hline \multirow[b]{2}{*}{ Sample } & \multirow[b]{2}{*}{ Steel Code } & \multirow[b]{2}{*}{ Reference } & \multicolumn{4}{|c|}{ Parameters from Best Fits } & \multirow[b]{2}{*}{$N_{\text {eff }}$} & \multirow[b]{2}{*}{$K_{1} \Gamma\left(\mathrm{J} \mathrm{mol}^{-1} \mathrm{~K}^{-1}\right)$} & \multirow{2}{*}{$\begin{array}{c}\text { Eq. [16] } \\
Q_{b}\left(\mathrm{~kJ} \mathrm{~mol}^{-1}\right)\end{array}$} \\
\hline & & & $T_{h}\left({ }^{\circ} \mathrm{C}\right)$ & $\lambda$ & $Q_{b}\left(\mathrm{~kJ} \mathrm{~mol}^{-1}\right)$ & $v B\left(\mathrm{~K}^{-1} \mathrm{~s}^{-1}\right)$ & & & \\
\hline 1 & $\mathrm{Fe}-0.15 \mathrm{C}-3 \mathrm{Cr}$ & 4, p. 205 & 594 & 35 & 34 & 0.012 & 10 & 188 & 21 \\
\hline 2 & $\mathrm{Fe}-0.26 \mathrm{C}-3 \mathrm{Cr}$ & 4 , p. 207 & 521 & 40 & 33 & 0.0042 & 10 & 197 & 33 \\
\hline 3 & $\mathrm{Fe}-0.15 \mathrm{C}$ & 1, p. 227 & 507 & 40 & 25 & 0.0004 & 7 & 208 & 28 \\
\hline 4 & $\mathrm{Fe}-0.29 \mathrm{C}-7 \mathrm{Ni}$ & 1, p. 153 & 573 & 25 & 36 & 0.0047 & 8 & 190 & 38 \\
\hline 5 & $\mathrm{Fe}-0.12 \mathrm{C}$ & 1, p. 523 & 584 & 80 & 32 & 0.0018 & 6 & 192 & 39 \\
\hline 6 & SAE 4150 & 2, p. 141 & 538 & 45 & 56 & 0.14 & 8 & 162 & 65 \\
\hline 7 & SAE 4330 & 1, p. 327 & 510 & 90 & 51 & 0.025 & 3 & 162 & 49 \\
\hline 8 & $\mathrm{Fe}-0.27 \mathrm{C}$ & 1, p. 333 & 510 & 50 & 52 & 0.047 & 6.5 & 166 & 42 \\
\hline 9 & $\mathrm{Fe}-0.29 \mathrm{C}-\mathrm{Mo}$ & 4, p. 52 & 584 & 45 & 52 & 0.075 & 7.5 & 166 & 58 \\
\hline 10 & $\mathrm{Fe}-0.38 \mathrm{C}-3 \mathrm{Cr}$ & 1, p. 53 & 508 & 95 & 43 & 0.0048 & 4 & 178 & 42 \\
\hline 11 & $\mathrm{Fe}-0.42 \mathrm{C}-1 \mathrm{Cr}$ & 1, p. 177 & 563 & 70 & 57 & 0.14 & 5 & 153 & 58 \\
\hline 12 & En 25 & 1, p. 100 & 486 & 50 & 53 & 0.087 & 7.5 & 164 & 57 \\
\hline 13 & En23 & 1, p. 100 & 533 & 45 & 58 & 0.13 & 6.5 & 158 & 49 \\
\hline 14 & En24 & 1, p. 101 & 530 & 70 & 54 & 0.055 & 6.5 & 165 & 54 \\
\hline 15 & En 100 & 1, p. 101 & 541 & 60 & 57 & 0.12 & 6 & 157 & 60 \\
\hline 16 & En 110 & 5, p. 100 & 531 & 70 & 63 & 0.35 & 7.5 & 153 & 52 \\
\hline 17 & En36 & 5, p. 106 & 458 & 35 & 76 & 3.37 & 8 & 135 & 75 \\
\hline 18 & En 11 & 5, p. 96 & 579 & 40 & 71 & 1.60 & 7.5 & 140 & 65 \\
\hline 19 & En17 & 5, p. 97 & 548 & 60 & 57 & 0.20 & 8 & 159 & 64 \\
\hline 20 & En 18 & 5, p. 96 & 569 & 65 & 61 & 0.32 & 6.5 & 151 & 57 \\
\hline 21 & NE 8949 & 1, p. 350 & 551 & 50 & 63 & 0.51 & 7 & 148 & 70 \\
\hline 22 & NE 9540 & 1, p. 373 & 526 & 30 & 65 & 1.16 & 10 & 150 & 63 \\
\hline 23 & $3310(0.6$ pct $C)$ & 5, p. 33 & 465 & 65 & 59 & 0.10 & 6 & 159 & 64 \\
\hline 24 & $3310(0.8$ pct $C)$ & 5, p. 33 & 421 & 65 & 75 & 1.13 & 7 & 142 & 82 \\
\hline 25 & $\mathrm{Fe}-0.39 \mathrm{C}-\mathrm{Mo}$ & 4, p. 55 & 515 & 50 & 70 & 0.93 & 7.5 & 145 & 67 \\
\hline 26 & $\mathrm{Fe}-0.39 \mathrm{C}-\mathrm{Ni}-\mathrm{Mo}$ & 1, p. 461 & 542 & 55 & 63 & 0.24 & 7 & 155 & 66 \\
\hline 27 & $\mathrm{Fe}-0.51 \mathrm{C}$ & 4, p. 184 & 462 & 50 & 71 & 0.74 & 7 & 145 & 70 \\
\hline 28 & $\mathrm{Fe}-0.55 \mathrm{C}$ & 4, p. 185 & 548 & 40 & 59 & 0.28 & 8 & 156 & 62 \\
\hline 29 & $\mathrm{Fe}-0.72 \mathrm{C}-\mathrm{Mo}$ & 1, p. 121 & 606 & 50 & 83 & 7.44 & 6.5 & 124 & 83 \\
\hline 30 & $\mathrm{Fe}-0.52 \mathrm{C}-\mathrm{Mn}$ & 1, p. 202 & 573 & 40 & 84 & 8.90 & 7 & 124 & 71 \\
\hline 31 & $\mathrm{Fe}-0.80 \mathrm{C}-\mathrm{Mo}$ & 1, p. 120 & 529 & 45 & 104 & 263 & 7 & 96 & 97 \\
\hline 32 & $\mathrm{Fe}-0.77 \mathrm{C}-\mathrm{Mo}$ & 1, p. 124 & 573 & 55 & 108 & 475 & 7 & 91 & 99 \\
\hline 33 & $\mathrm{Fe}-0.79 \mathrm{C}-\mathrm{Mo}$ & 1, p. 130 & 544 & 55 & 104 & 175 & 7 & 100 & 104 \\
\hline 34 & $\mathrm{Fe}-0.97 \mathrm{C}$ & 1, p. 312 & 464 & 95 & 97 & 23.2 & 3 & 105 & 108 \\
\hline 35 & $\mathrm{Fe}-1.04 \mathrm{C}-4 \mathrm{Cr}$ & 1, p. 58 & 383 & 95 & 100 & 41.1 & 2 & 97 & 105 \\
\hline 36 & $\mathrm{Fe}-0.98 \mathrm{C}-\mathrm{Mn}-\mathrm{Si}$ & 31 & 339 & 90 & 132 & 57,907 & 7 & 51 & 135 \\
\hline 37 & $\mathrm{Fe}-0.8 \mathrm{C}-2 \mathrm{Mn}$ & 1, p. 92 & 521 & 55 & 98 & 304 & 8 & 98 & 90 \\
\hline 38 & $\mathrm{Fe}-1.2 \mathrm{C}-2 \mathrm{Mn}$ & 1, p. 93 & 440 & 70 & 123 & 12,946 & 8 & 67 & 126 \\
\hline 39 & $\mathrm{Fe}-0.79 \mathrm{C}-5 \mathrm{Ni}$ & 1, p. 147 & 488 & 70 & 85 & 3.71 & 6 & 129 & 82 \\
\hline 40 & $\mathrm{Fe}-0.80 \mathrm{C}-5 \mathrm{Ni}$ & 1, p. 145 & 482 & 85 & 86 & 12.0 & 6 & 119 & 86 \\
\hline
\end{tabular}




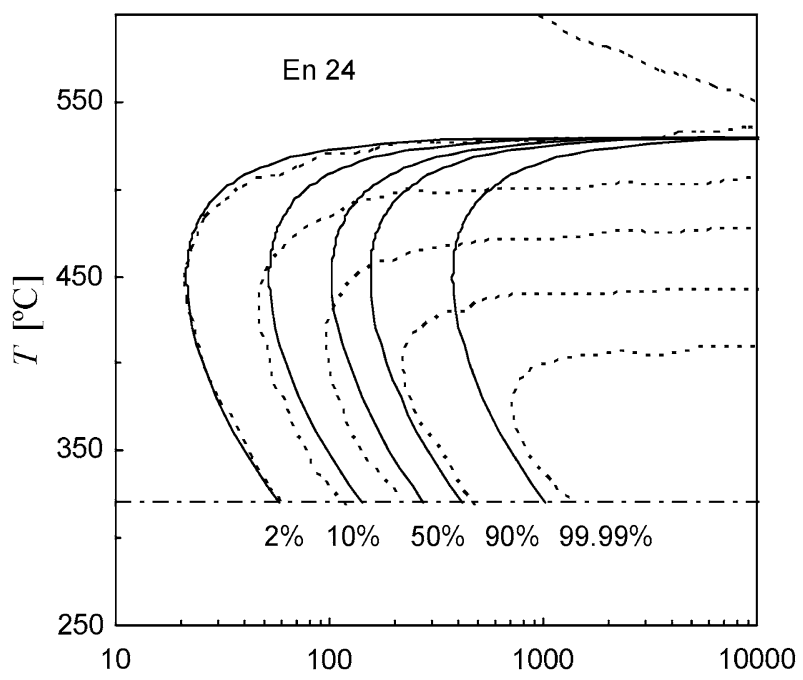

(a)

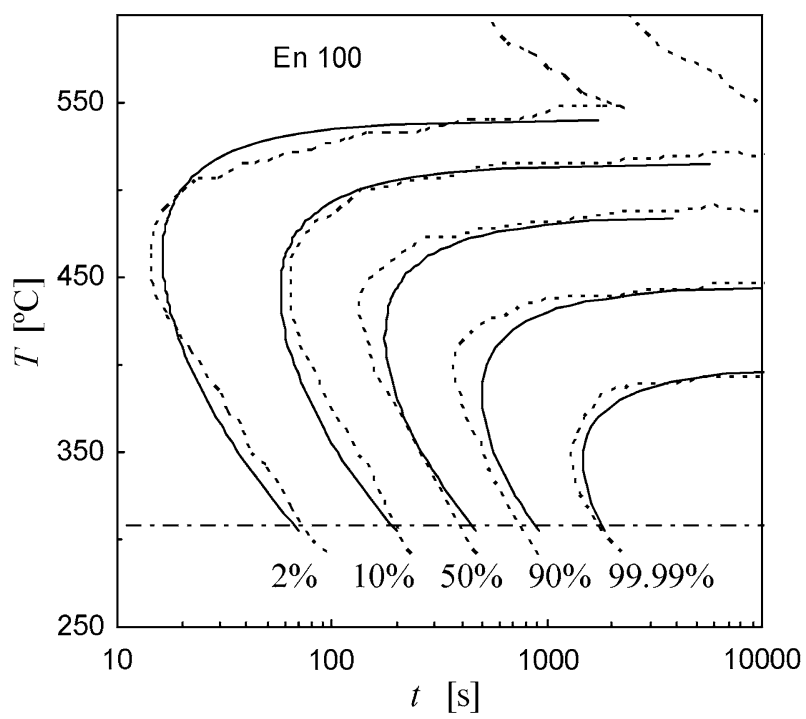

(b)

Fig. 2-Comparison between experimental (dotted line) and calculated (solid line) start curve of bainite formation in (a) En $24^{[1]}$ and (b) En 100. ${ }^{[5]}$ For En 100, the additional 10, 50, 90, and 99.9 pct curves are calculated with the highest temperatures, in accordance with the method suggested by Steven and Haynes. ${ }^{[27]}$

steels, this incomplete transformation effect was already noted and was quantified to some extent. They simply argued that with some resemblance to the martensitic transformation, the final extent of the bainitic transformation is also temperature dependent. ${ }^{[27]}$ For the steels investigated in Reference 27, the temperatures above which more than 50 pct bainite will not form $\left(B_{50}\right)$ are reported and, on average, this temperature was found to be $60{ }^{\circ} \mathrm{C}$ lower than the $B_{s}$ temperature.

Analogous to the method proposed in Reference 27, the $10,50,90$, and 100 pct curves have been calculated for steel En $100^{[5]}$ to realize the best agreement with the experimental data as shown in Figure 2(b). The $B_{S}$ temperature of En 100 is $541{ }^{\circ} \mathrm{C}$, and the temperatures used in the simulations of the additional curves are

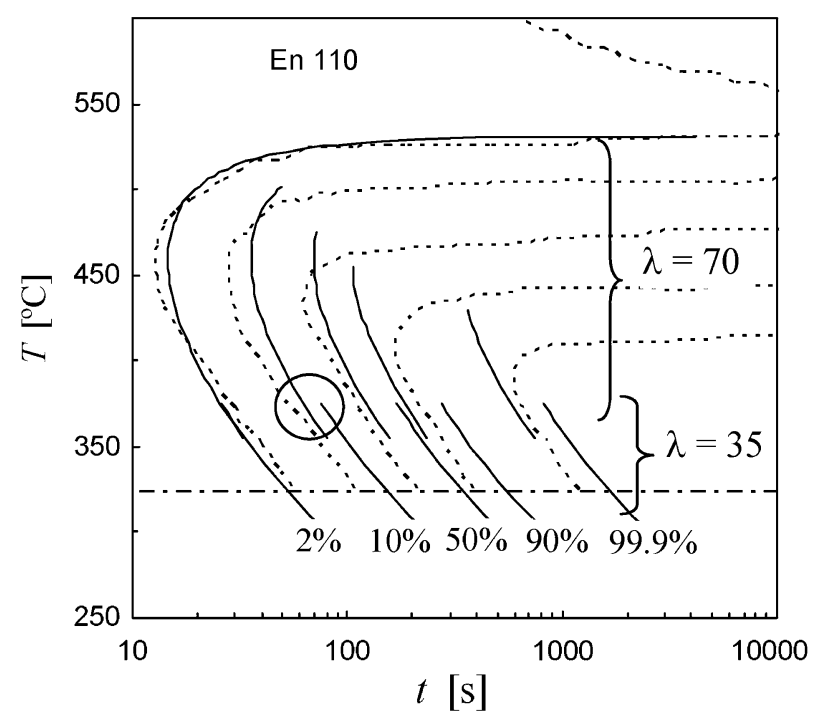

Fig. 3-Experimental (dotted line) and calculated (solid line) TTT diagram of En $110^{[5]}$ illustrating the effect of $\lambda$ (70 or 35) on the fit of the additional curves.

$B_{10}=516{ }^{\circ} \mathrm{C}, B_{50}=486{ }^{\circ} \mathrm{C}, B_{90}=446{ }^{\circ} \mathrm{C}$, and $B_{99}=$ $401{ }^{\circ} \mathrm{C}$. Although this example demonstrates that the idea of Steven and Haynes can account for the temperature dependence of the final extent of the transformation, the exact mechanism by which the austenite is stabilized during bainite formation in lean-Si steels at relatively high temperatures remains unexplained. Therefore, this scheme has not been pursued in the simulations of the additional curves for the other alloys. This stabilization phenomenon is very interesting, but goes beyond the scope of the present investigation and requires further research.

Figure 3 shows the comparison between the calculated and experimental start curve of steel En 110. ${ }^{[5]}$ An agreement is obtained similar to that for the steels En 24 and En 100 (Figure 2). Furthermore, the activation energy $Q_{b}=63 \mathrm{~kJ} \mathrm{~mol}^{-1}$ used in the calculation for En 110 is only slightly larger than the $Q_{b}=54$ and $57 \mathrm{~kJ} \mathrm{~mol}^{-1}$ found for En 24 and En 100, respectively. Consistent with this comparison in $Q_{b}$, the shape of the start curves is also similar for all three B.S. En steels. To demonstrate the effect of the autocatalytic parameter $\lambda$ on the fit of the additional curves, the simulated curves for two different $\lambda$ values are shown in Figure 3 , namely $\lambda=70$ for temperatures in the range $350^{\circ} \mathrm{C}$ to $540{ }^{\circ} \mathrm{C}$, and $\lambda=35$ for temperatures below $360^{\circ} \mathrm{C}$. The region of overlap between both simulations, indicated by the encircled region in Figure 3, shows that the overall agreement with the experimental data of the additional curves is better for the calculations using $\lambda=70$. For the calculations with $\lambda=35$, the same agreement with the start curve was achieved by using a $B$ value of $0.42 \times 10^{-13} \mathrm{~K}^{-1}$, which is approximately 20 pct larger than $B=0.35 \times 10^{-13} \mathrm{~K}^{-1}$ used for $\lambda=70$. This example explains the basis on which $\lambda$ is determined and gives insight into the uncertainties in $\lambda$ and the consequence for the evaluated parameter $B$. As mentioned earlier, the inaccuracy in $B$ due to the uncertainty 
in $f_{\text {start }}$ is considerably larger, and in the evaluation of the model parameters, this uncertainty will be discussed.

In Figure 4, the calculated transformation curves (solid lines) are compared with the experimental data of $\mathrm{Fe}-0.42 \mathrm{C}-1 \mathrm{Cr}$ and $\mathrm{Fe}-0.38 \mathrm{C}-3 \mathrm{Cr}$ measured by Klier and Lyman. ${ }^{[26]}$ These two TTT diagrams are interesting, in particular because the experimental data points are shown together with the corresponding fractions. Such detailed information is frequently not given and the scatter in the experimental data offers valuable insight into the experimental inaccuracies involved in the construction of TTT diagrams. Figure 4(a) shows that for $\mathrm{Fe}-0.42 \mathrm{C}-1 \mathrm{Cr}$, both the calculated 2.5 and $97.5 \mathrm{pct}$ curves are in excellent agreement with the experimental data points corresponding to these fractions, as evaluated from dilatometry measurements. ${ }^{[26]}$ This optimal agreement for the two curves is achieved using $\lambda=70$. The three experimental data points (open squares) in Figure 4(a), which are reported to identify the start of the transformation as deduced from metallographic analysis, ${ }^{[26]}$ are best described by the model when it is assumed that these data points correspond to $1 \mathrm{pct}$ transformation. This seems to be a realistic fraction. In addition, for $\mathrm{Fe}-0.38 \mathrm{C}-3 \mathrm{Cr}$, the experimental data points corresponding to $0.5 \mathrm{pct}$ transformation are well described by the model, as seen in Figure 4(b). However, the agreement with the 99.5 pct dilatometry data is not optimal.

Figure 5 shows the agreement between the calculated start curve (solid line) for Fe-0.98C-1.89Mn-1.46Si and the experimental data (solid circles) measured by Caballero et al. ${ }^{[31]}$ This alloy transforms to bainite at very low temperatures and the as-formed bainitic microstructure is very strong due to the fine lath structure. ${ }^{[31]}$ The dashed line in Figure 5 indicates the start curve calculated with the model of Bhadeshia. ${ }^{[6,9]}$ In this highalloyed steel, the transformation kinetics decrease strongly with decreasing temperature, i.e., the $\mathrm{C}$ shape is very pronounced and this is associated with a large activation energy, $Q_{b}=132 \mathrm{~kJ} \mathrm{~mol}^{-1}$, which is the largest $Q_{b}$ found for all the investigated alloys.

The experimental TTT diagram of $\mathrm{Fe}-0.79 \mathrm{C}-5 \mathrm{Ni}^{[1]}$ is shown in Figure 6 together with the best fit (solid line) of the data in the temperature range of bainite formation. This high-carbon steel has no significant $\mathrm{Cr}$ or $\mathrm{Mo}$ addition and, consequently, the bay region is absent. However, in the reported TTT diagram, it is clearly indicated that the lower part of the single $\mathrm{C}$ curve corresponds to bainite formation. By estimating $T_{h}$, the data are fitted to the model, and a value $Q_{b}=85$ $\mathrm{kJ} \mathrm{mol}^{-1}$ is extracted from the best fit.

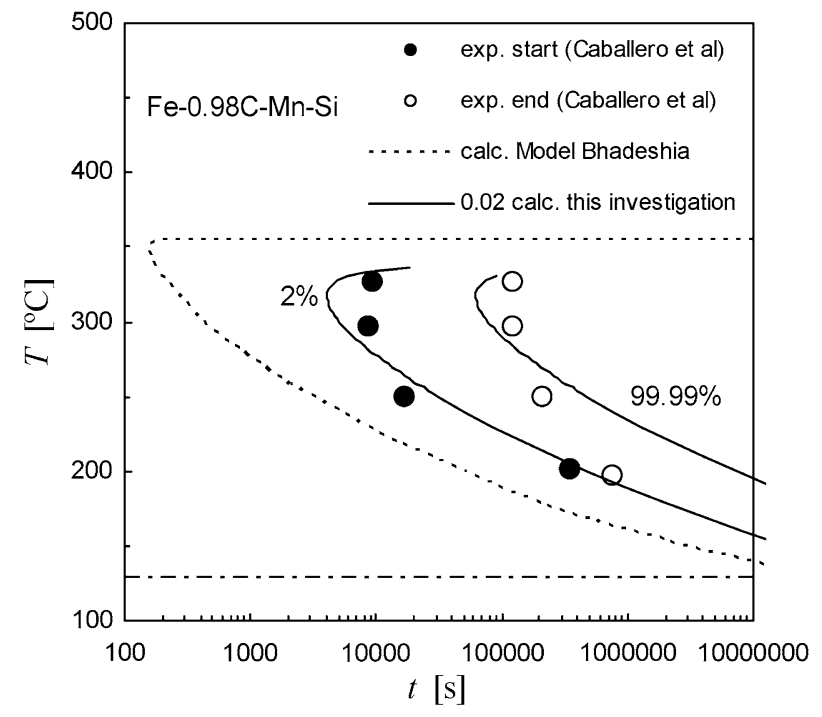

Fig. 5-Calculated start curve (solid line) for Fe-0.98C-Mn-Si compared to the experimental data (solid circles). ${ }^{[31]}$ The dashed line indicates the start curve calculated with the model of Bhadeshia. ${ }^{[9]}$

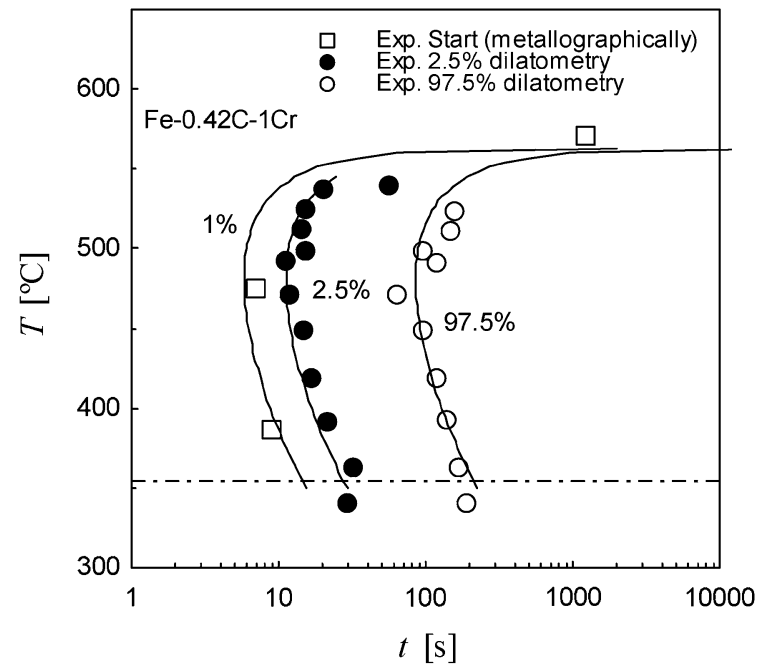

(a)

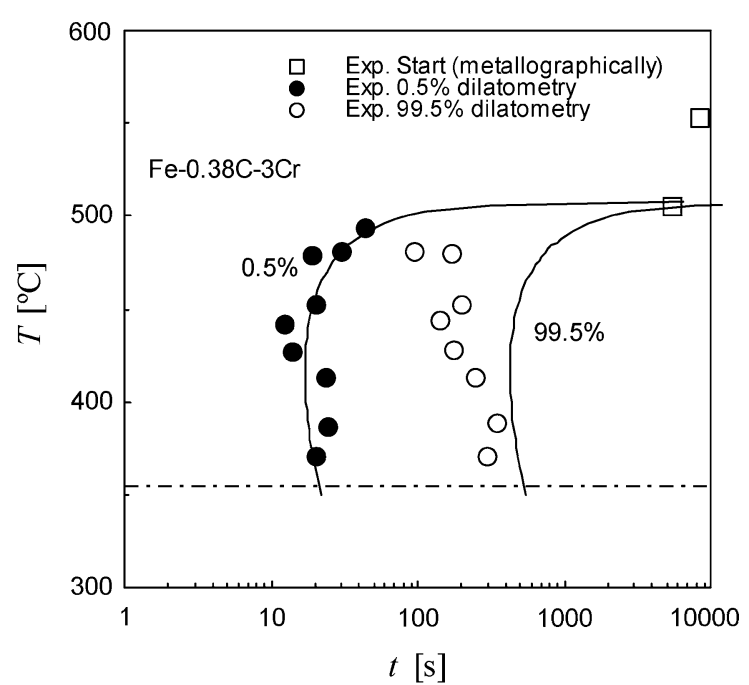

(b)

Fig. 4-TTT diagrams of (a) Fe- $0.42 \mathrm{C}-1 \mathrm{Cr}$ and (b) Fe-0.38C-3Cr showing the degree of agreement between experimental data (Klier and Lyman ${ }^{[26]}$ ) and calculated transformation curves (solid lines). 


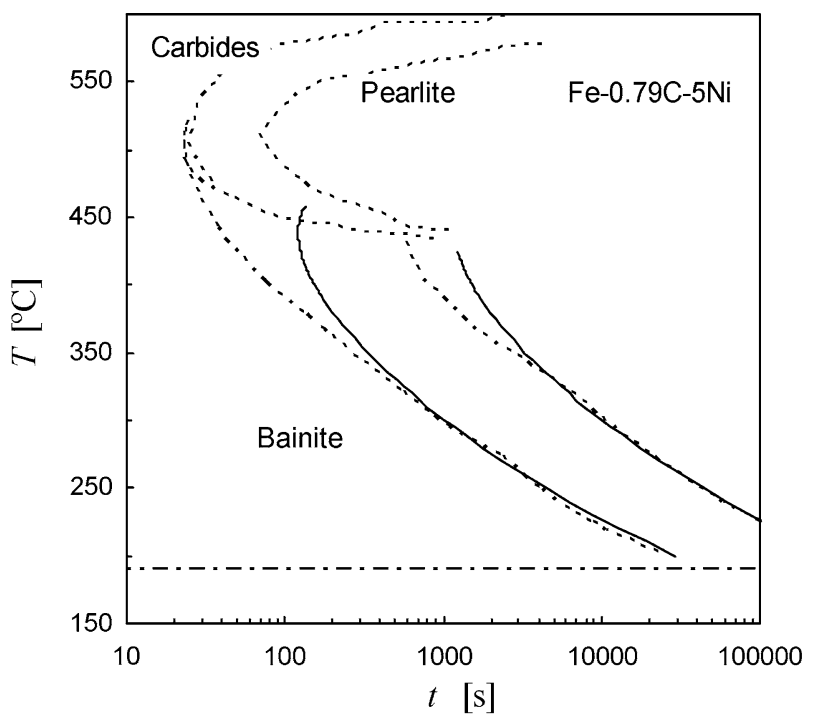

Fig. 6-TTT diagram of $\mathrm{Fe}-0.79 \mathrm{C}-5 \mathrm{Ni}^{[1]}$ showing the agreement between the calculated kinetics (solid line) and the experimental start curve in the temperature range of bainite formation. Bainite start curve has a strong overlap with the start curve of carbides due to the very low $\mathrm{Cr} / \mathrm{Mo}$ content of this alloy.

Figure 7 shows the experimental and calculated start curves of six steels ${ }^{[1,4]}$ that have very different transformation kinetics. In agreement with the observed differences in the $\mathrm{C}$ shape of the start curves, the values of $Q_{b}$ deduced from the best fits show a strong variation. The characteristic $\mathrm{C}$ shape of the start curve is related to certain alloying elements. Later in this article, a more quantitative analysis will be given to derive a relationship between $Q_{b}$ and the composition.

Because of space restrictions, the TTT diagrams of the other alloys cannot be included in the present article, but a comparable agreement, as seen in Figures 2 through 7, has been obtained for the other steels. (For the online version, the supplement to this manuscript shows the other TTT diagrams of alloys listed in Table I.)

\section{DISCUSSION}

\section{A. Correlation between $B$ and $Q_{b}$}

The dependence between the parameters $B$ and $Q_{b}$ extracted from the best fits (Table II) is shown in Figure 8(a), which plots the values of $v B$ $\left(v=1 \times 10^{13} \mathrm{~s}^{-1}\right)$ on a logarithmic scale against $Q_{b}$. This figure shows a clear correlation between $B$ and $Q_{b}$, which is a remarkable outcome of this analysis. Apparently, there exists a material-independent exponential relationship between $B$ and $Q_{b}$, which are the essential parameters describing the transformation kinetics of bainite in the wide range of steels investigated. In fact, it will be shown later that this finding is consistent with the known details of the nucleation mechanism of bainite based on a dislocation process. ${ }^{[9]}$

The uncertainty in $f_{\text {start }}$ leads to inaccuracies in the parameter $B$, which is indicated for a few data points in Figure 8 (a) by the vertical error bars. The fraction

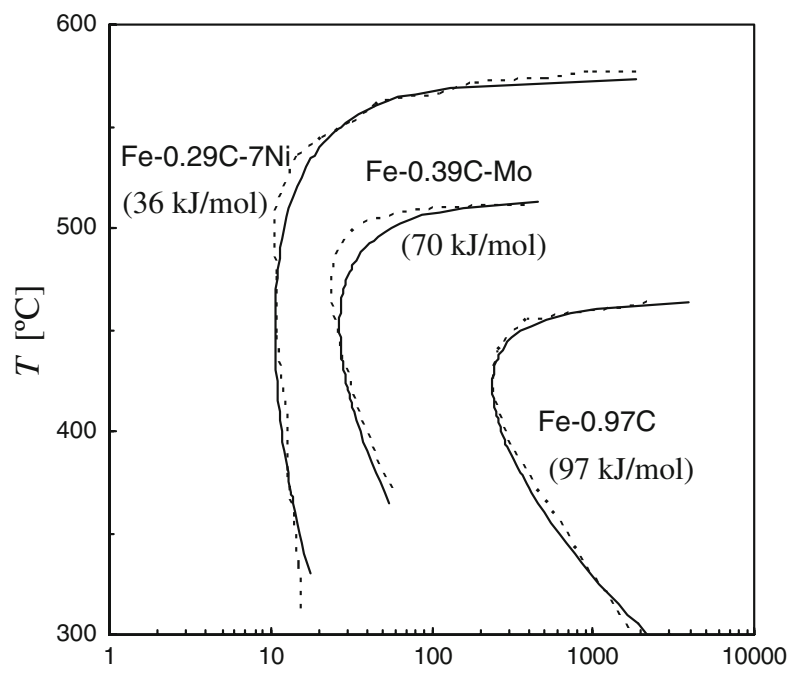

(a)

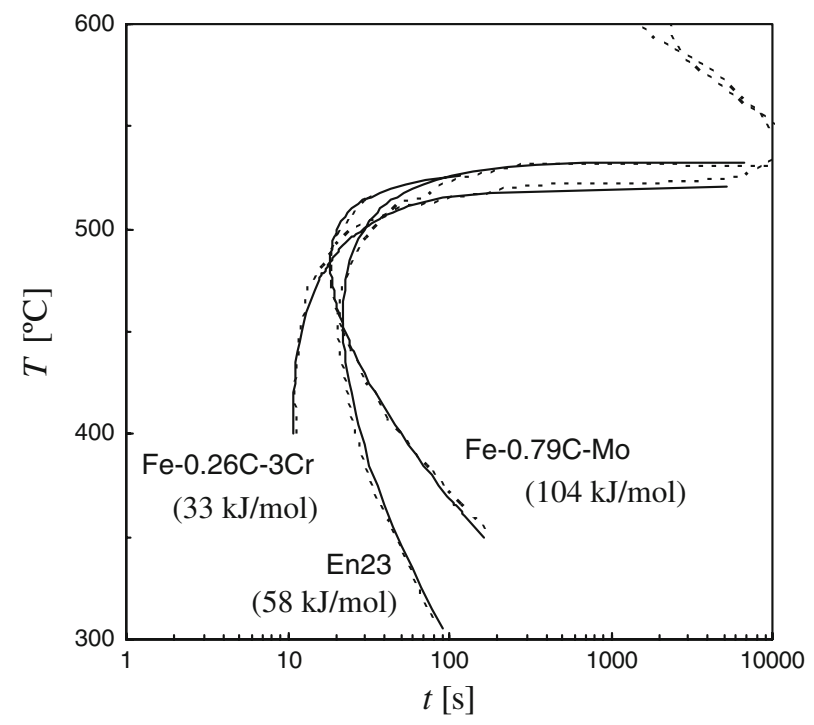

(b)

Fig. 7-Comparison between the experimental (dotted lines) and calculated (solid lines) start curves for six alloys listed in Table $\mathrm{I}^{[1,4]}$ The two diagrams show the change in the shape of the start curve with varying activation energy $Q_{b}$, which is indicated by the number in parentheses.

corresponding to the experimental start curve $f_{\text {start }}$ is assumed to be 2 vol pct but may have a different value in the range of 0.7 to 4 vol pct, which implies smaller or larger $B$ values, respectively, as indicated by the error bars. For a few data points, diagonal error bars are also shown, which indicate the correlated uncertainty in the two model parameters $B$ and $Q_{b}$. When both $B$ and $Q_{b}$ are chosen, somewhat smaller or larger than the values corresponding to the best fit (Table II), the agreement with the experimental data decreases but can still be regarded as acceptable.

It is noted that the pre-exponential factor $B$ is related to the number density of potential nucleation sites $N_{i}$; however, the observed variation in $B$ of six orders of magnitude cannot be understood to be a realistic material dependence of $N_{i}$. Assuming no material 


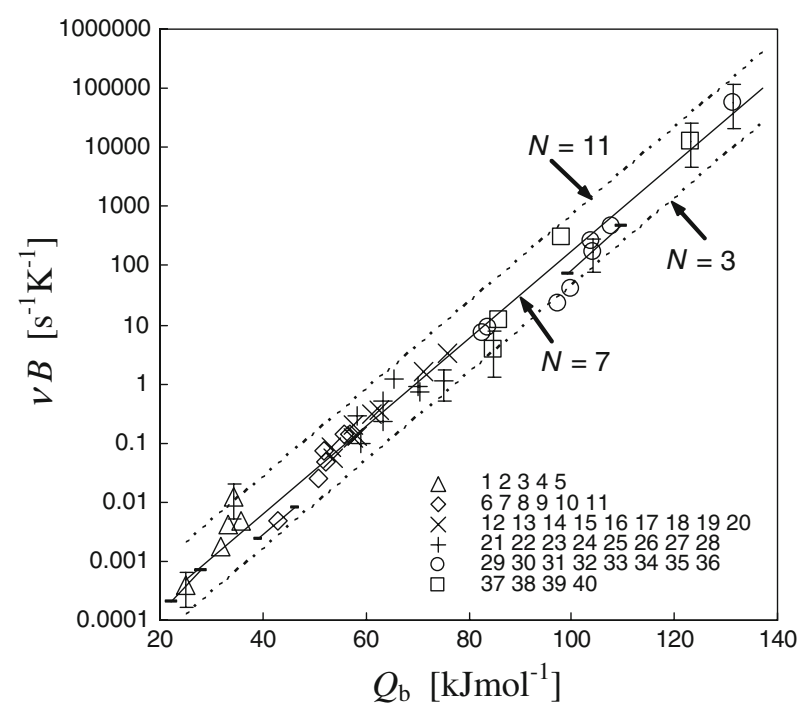

(a)

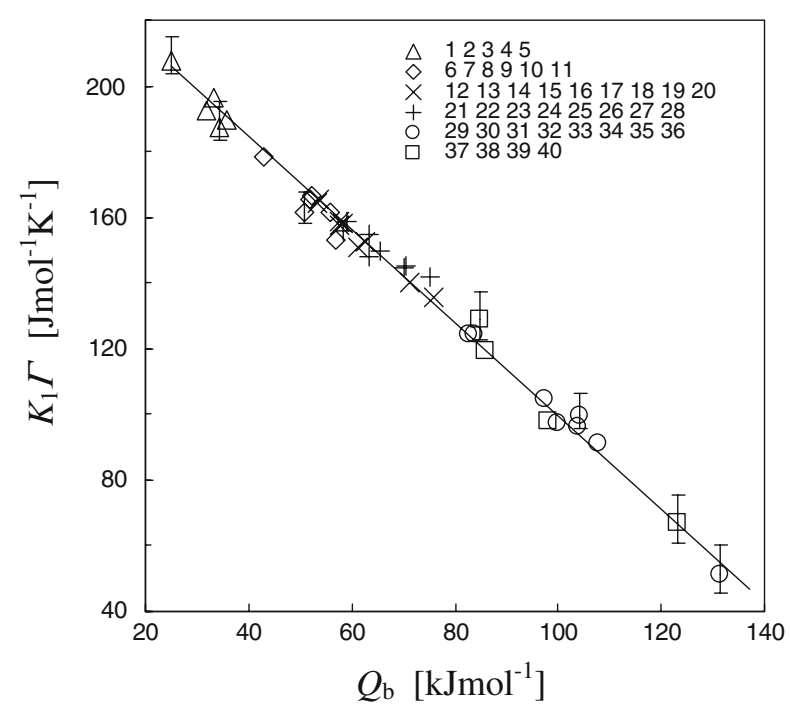

(b)

Fig. 8- (a) Values of $v B$ as a function of $Q_{b}$ (Table II). Solid line is calculated based on $N=7$ and Eq. [11]. Vertical error bars are related to the uncertainty in $f_{\text {start }}\left(0.7\right.$ to 4 vol pct). (b) Values of $K_{1} \Gamma$ evaluated from the $B$ values fitted to the solid line, $K_{1} \Gamma=\left(170 \mathrm{~kJ} \mathrm{~mol}^{-1}-Q_{b}\right) /(705 \mathrm{~K})$.

dependence, $\alpha_{b}$ is calculated according to Eq. [4] as $\alpha_{b}=\left(9 \times 10^{-5} \mu \mathrm{m} \mathrm{K}^{-1}\right) / d^{\prime}$. For $N=7\left(d^{\prime}=32 \mu \mathrm{m}\right)$, which is approximately the average austenite grain size of the steels investigated, $\alpha_{b}=2.8 \times 10^{-6} \mathrm{~K}^{-1}$, and the solid line in Figure 8 (a) describes $B$ as a function of $Q_{b}$ according to

$$
B=\alpha_{b} \exp \left(-\frac{Q_{d}-Q_{b}}{\mathrm{R} T_{d}}\right)
$$

with the composition-independent parameters $Q_{d}=$ $170 \mathrm{~kJ} \mathrm{~mol}^{-1}$ and $T_{d}=705 \mathrm{~K}\left(432^{\circ} \mathrm{C}\right)$. Alloys with $N>7$ and $N<7$ have $B$ values above and below this calculated line, respectively. Calculations with Eq. [11] using $N=3$ and 11 are indicated by the dashed lines in
Figure $8(\mathrm{a})$, and it is seen that all data are within this range.

When Eq. [9], which describes the relationship between $K_{1} \Gamma$ and $B$, is combined with Eq. [11], it follows that $K_{1} \Gamma=\left(170 \mathrm{~kJ} \mathrm{~mol}^{-1}-Q_{b}\right) /(705 \mathrm{~K})$, which is indicated by the solid line in Figure 8(b). The values of $K_{1} \Gamma$ can be evaluated from the $B$ values listed in Table II using Eq. [9] and the parameter $\alpha_{b}$, which is a function of the grain size. The agreement between the values of $K_{1} \Gamma$ and the relationship $K_{1} \Gamma=(170$ $\left.\mathrm{kJ} \mathrm{mol}^{-1}-Q_{b}\right) /(705 \mathrm{~K})$ is optimized by adjusting the effective austenite grain size $N_{\text {eff }}$. In view of experimental inaccuracies, it is considered acceptable that $N_{\text {eff }}$ deviates \pm 1 ASTM number from the reported grain size $N$ (Table I). Table II shows the values of $N_{\text {eff }}$ and $K_{1} \Gamma$. It can be seen that for most steels, $N_{\text {eff }}$ is equal to the reported ASTM number $N$, and Figure 8(b) shows a satisfactory agreement between the evaluated values of $K_{1} \Gamma$ and the relationship $K_{1} \Gamma=\left(170 \mathrm{~kJ} \mathrm{~mol}^{-1}-Q_{b}\right) /$ $(705 \mathrm{~K})$. An error estimate of the constants in Eq. [11] is made by calculating the just-acceptable fits through the data, which leads to the two limiting equations, $K_{1} \Gamma=$ $\left(166 \mathrm{~kJ} \mathrm{~mol}^{-1}-Q_{b}\right) /(683 \mathrm{~K})$ and $K_{1} \Gamma=\left(175 \mathrm{~kJ} \mathrm{~mol}^{-1}\right.$ $\left.-Q_{b}\right) /(735 \mathrm{~K})$.

\section{B. Activation Energy $Q^{*}$}

By using the established relationship $Q_{b}=Q_{d}-$ $K_{1} \Gamma T_{d}$ and Eq. [9], the rate parameter $\kappa$ (Eq. [7]) can be written as

$$
\begin{aligned}
\kappa= & v \frac{9 \times 10^{-5} \mu \mathrm{m} \mathrm{K}^{-1}}{d_{\mathrm{eff}}}\left(T_{h}-T\right) \\
& \times \exp \left(-\frac{\left(Q_{d}-K_{1} \Gamma T_{d}+K_{1} \Gamma T\right)}{\mathrm{R} T}\right)
\end{aligned}
$$

The activation energy $Q^{*}$ in this equation can be rewritten using the material parameter $T_{1}$ to show the dependence on the driving force, $\Delta G_{m}=\Gamma\left(T_{1}-T\right)$, in a similar way as in Eq. [5], which leads to

$$
Q^{*}=Q_{d}+K_{1} \Gamma\left(T_{1}-T_{d}\right)-K_{1} \Gamma\left(T_{1}-T\right)
$$

This expression closely resembles the expression of $Q^{*}$ in the model derived by Bhadeshia for the nucleation of bainite involving the dissociation of dislocations. ${ }^{[9]}$ In this model, which is based on the work of Cohen and Olson, ${ }^{[23]}$ the activation energy $Q^{*}$ originates from the resistance of the lattice to the motion of dislocations and is described by ${ }^{[9]}$

$$
Q^{*}=G_{0}^{*}+\left[\tau_{\mu}+\frac{\rho_{\mathrm{A}}}{\mathbf{b}} G_{\text {strain }}+\frac{2 \sigma}{n_{P} \mathbf{b}}\right] v^{*}-\frac{\rho_{A} v^{*}}{\mathbf{b}} \Delta G_{m}
$$

By comparison of Eqs. [13] and [14], with respect to the term describing the proportionality with the driving force, it is found that the parameter $K_{1}$ can be expressed as

$$
K_{1}=\frac{\rho_{A} v^{*}}{\mathbf{b}}
$$

where $v^{*}$ is an activation volume, $\mathbf{b}$ the magnitude of the Burgers vector, and $\rho_{A}$ the spacing of the close-packed 
planes on which the faulting is assumed to occur. ${ }^{[9]}$ It is important to note that in agreement with Eq. [14], the second term in Eq. [13] is also proportional to $K_{1}$ or, equivalently, is proportional to the activation volume.

According to Eq. [14], the temperature-independent part of $Q^{*}$ is dependent on many material parameters such as $\tau_{\mu}$, the temperature-independent resistance to dislocation motion; $G_{\text {strain, }}$ the strain energy per unit volume of $\alpha$; $\sigma$, the $\alpha / \gamma$ interfacial energy; and $n_{P}$, the number of close-packed planes participating in the faulting process. A comparison of Eqs. [13] and [14] also suggests that $Q_{d}\left(170 \mathrm{~kJ} \mathrm{~mol}^{-1}\right)$ can be identified as the constant $G_{0}^{*}$, the energy barrier between adjacent equilibrium positions partial dislocations.

\section{Empirical Relationship for $Q_{b}$}

In many previous experimental investigations, it was already proposed that the chemical composition has an influence on the characteristic $C$ shape of the start curve. ${ }^{[5]}$ This understanding was based on the accumulated knowledge in the construction of TTT diagrams. In the present study, the $\mathrm{C}$ shape of the start curve is unambiguously related to $Q_{b}$, and an attempt has been made to develop an empirical equation for $Q_{b}$ as a function of the chemical composition such that predictions of the shape of start curves can be made. It is known that the alloying elements differ in the nature and magnitude of their effect on the transformation to bainite and that the combined effect on the transformation behavior can be rather complex. ${ }^{[5]}$ As a starting point, it is assumed that $Q_{b}$ has a linear dependence on the concentration of alloying elements. Based on a statistical analysis of the data (Table II) using the method of least squares, an empirical relationship between $Q_{b}$ and composition has been developed as described by

$$
\begin{aligned}
Q_{b}\left(\mathrm{~kJ} \mathrm{~mol}^{-1}\right)= & 89 x_{\mathrm{C}}+10 x_{\mathrm{Mn}}+12 x_{\mathrm{Si}}+2 x_{\mathrm{Cr}} \\
& +1 x_{\mathrm{Ni}}+29 x_{\mathrm{Mo}}
\end{aligned}
$$

with the concentration $x$ in weight percent. The values of $Q_{b}$ calculated with Eq. [16] are given in Table II for comparison with the values of $Q_{b}$ evaluated from the best fits. Figure 9 shows an adequate agreement between the calculated and measured values of $Q_{b}$. The standard error associated with the statistical analysis underlying Eq. [16] is $6.0 \mathrm{~kJ} \mathrm{~mol}^{-1}$, and the corresponding $R^{2}$ coefficient is 0.94. An analysis of Eq. [16] shows that carbon increases $Q_{b}$ more markedly than any of the other alloying elements. It is also noteworthy that of all substitutional elements, Mo has the strongest effect on $Q_{b}$, while $\mathrm{Cr}$ is seen to have only a weak influence on $Q_{b}$.

\section{Predictions of Kinetics}

For a steel with a composition in the range of compositions analyzed in the present study, Eq. [16] can be used to predict the value of $Q_{b}$, which determines the C shape of the start curve. To predict the kinetics, the calculated $Q_{b}$ and the austenite grain size $d_{\text {eff }}$ are inserted in Eq. [11] in order to obtain the parameter $B$.

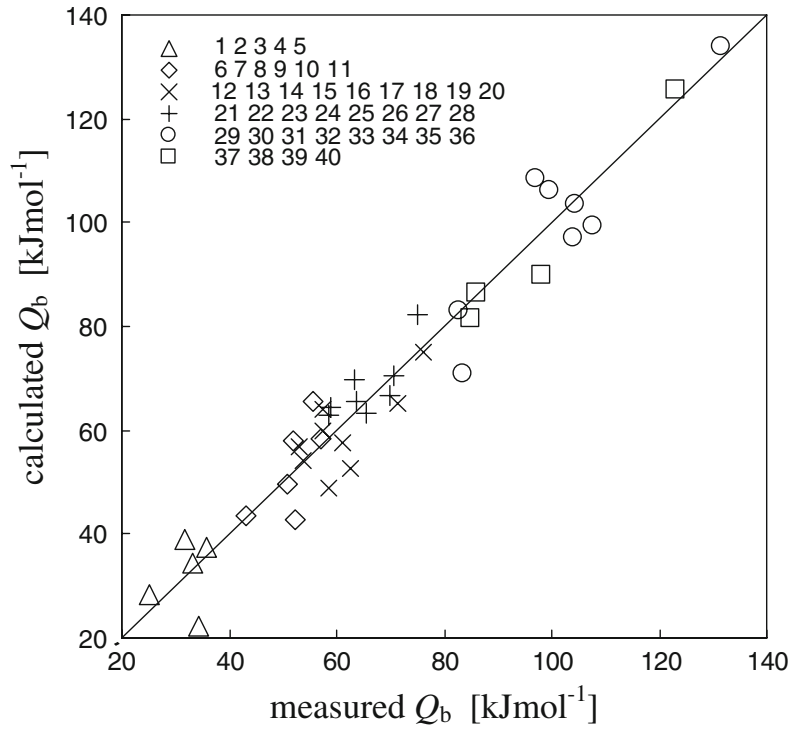

Fig. 9-Correlation between values of $Q_{b}$ calculated with the empirical relationship described in Eq. [16] and the measured values of $Q_{b}$ corresponding to the best fits (Table II).

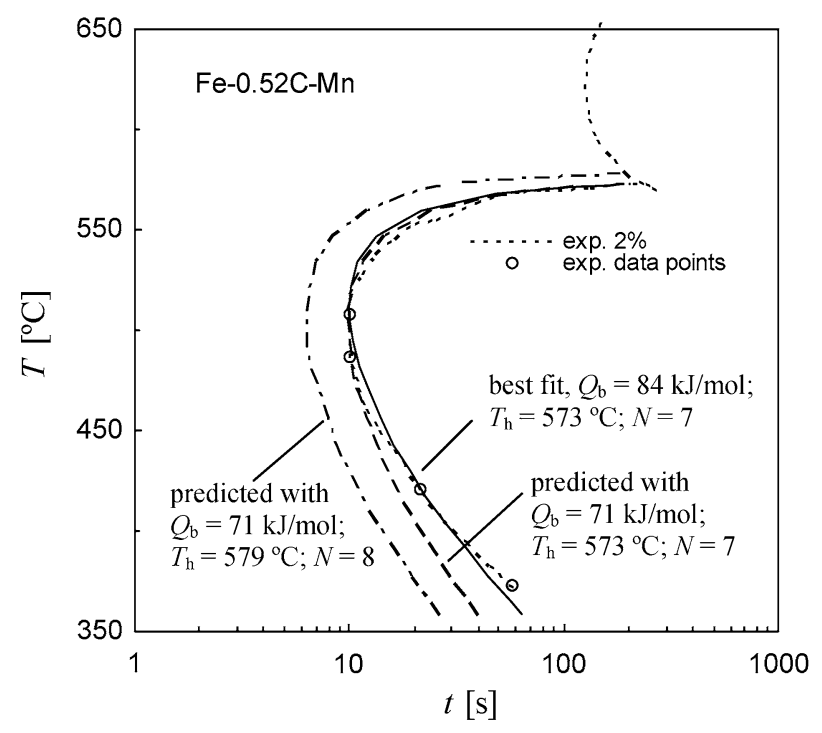

Fig. 10-Comparison between calculated best fit (solid line) of the experimental data $\left(\mathrm{Fe}-0.52 \mathrm{C}-\mathrm{Mn},{ }^{[1]}\right.$ open circles and dotted line) and the start curve calculated using $Q_{b}$ predicted by Eq. [16] (dashed line) and the fully predicted start curve (dashed-dotted line) based on Eqs. [16] and [17], respectively.

Subsequently, when $T_{h}$ is also known, the rate parameter $\kappa$ can be evaluated using Eq. [7], and together with $\lambda$, the kinetics can be predicted using Eq. [6]. To verify that adequate predictions can be made based on $Q_{b}$ calculated with Eq. [16], the start curve of Fe-0.52C$\mathrm{Mn}^{[1]}$ has been simulated according to the procedure described earlier, with $d_{\text {eff }}$ and $T_{h}$ equal to the values used in the calculation of the best fit. Figure 10 shows the comparison between this semipredicted start curve (dashed line) and the best fit (solid line). Table II shows that for $\mathrm{Fe}-0.52 \mathrm{C}-\mathrm{Mn}$, the difference between the predicted and measured $Q_{b}$ is relatively large, approximately 
$13 \mathrm{~kJ} \mathrm{~mol}^{-1}$, which means that this example demonstrates the least accurate prediction for the investigated dataset. Despite this strong discrepancy, it is seen in Figure 10 that the predicted start curve gives a fair approximation of the kinetics.

\section{E. Empirical Relationship for $T_{h}$}

Predictions of the bainite start temperature with the formula established by Steven and Haynes ${ }^{[27]}$ do not lead to an optimal agreement with the values of $T_{h}$ of the steels investigated in the present article (Table II). The origin of these deviations can be well explained by the analyzed data set. Steven and Haynes ${ }^{[27]}$ derived their empirical relationship of $B_{s}$ on the basis of results obtained for many B.S. En steels, whereas in the present study, many other, considerably different, steel codes are analyzed as well. Analogous to the Steven and Haynes approach, the influence of the composition on the $T_{h}$ of the steels shown in Table II can be described by a similar empirical equation, namely:

$$
\begin{aligned}
T_{h}\left({ }^{\circ} \mathrm{C}\right)= & 835-198 x_{\mathrm{C}}-91 x_{\mathrm{Mn}}-15 x_{\mathrm{Si}}-73 x_{\mathrm{Cr}} \\
& -36 x_{\mathrm{Ni}}-87 x_{\mathrm{Mo}}
\end{aligned}
$$

with the concentration $x$ in weight percent. Figure 11 shows that the values of $T_{h}$ calculated with Eq. [17] are in reasonable agreement with the measured values. From the linear regression analysis associated with the derivation of Eq. [17], it follows that the standard error and the $R^{2}$ coefficient are $23{ }^{\circ} \mathrm{C}$ and 0.84 , respectively. For comparison, the empirical equation established by Steven and Haynes ${ }^{[27]}$ tested against the present dataset leads to a standard error of $28^{\circ} \mathrm{C}$ and a correlation coefficient of 0.77 .

When both $Q_{b}$ and $T_{h}$ are calculated with Eqs. [16] and [17], respectively, the start curve can be fully

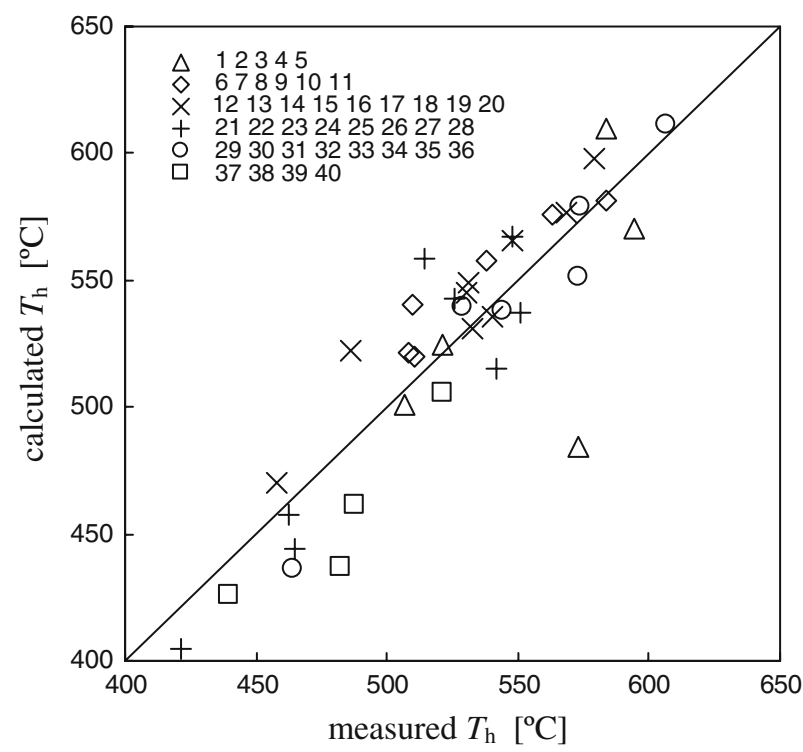

Fig. 11-Correlation between the values of $T_{h}$ extracted from the best fits (Table II) and the values of $T_{h}$ calculated with Eq. [17]. predicted. This is demonstrated for $\mathrm{Fe}-0.52 \mathrm{C}-\mathrm{Mn}$ in Figure 10, in which the dashed-dotted line has been calculated using $T_{h}=579{ }^{\circ} \mathrm{C}$, predicted by Eq. [17] in combination with $N=8$, the reported austenite grain size. Comparison with the other curves in Figure 10 shows that this fully predicted start curve (dasheddotted line) overestimates the overall kinetics, i.e., the curve is shifted to shorter times at all temperature levels. This comparison reveals the strong sensitivity on the austenite grain size. On the other hand, the predicted $T_{h}$ for this alloy is only $6{ }^{\circ} \mathrm{C}$ higher than the value derived from the best fit, which leads to a small shift of the start curve in the $T$ direction of the TTT diagram. This example of a fully predicted start curve gives a reasonable approximation of the overall pattern of the transformation; however, it should be noted that a much better representation of the kinetics can be given when the model can be tested against one precise experimental data point to derive $d_{\text {eff }}$.

\section{F. Additional Remarks}

To ensure an optimal transparency of the simulations and the interpretation of the model parameters in the foregoing, the values of $\delta$ and $\alpha_{m}$ were assumed constant in the calculations, which means that $\alpha_{b}$ is only dependent on the austenite grain size. However, it seems also reasonable to assume that $\alpha_{b}$ has a dependence on the composition as well, through $\delta$ and $\alpha_{m}$, although it is difficult to make justified assumptions regarding the material dependence of $\delta$. Therefore, any possible material dependence of $\alpha_{b}$ has been accounted for in the calculations by choosing an effective grain size, $d_{\text {eff. }}$. The values of $d_{\text {eff }}$ derived for the studied alloys did not differ much from the reported grain sizes, which indicates that the material dependence of $\alpha_{b}$ is weak.

\section{CONCLUSIONS}

It is shown that the model calculations give a very accurate description of the bainite start curve over the whole temperature range of transformation. In particular, the satisfactory prediction of the shape of the C curve in the region near the nose strongly supports that the number density of potential nucleation sites $N_{i}$ is proportional to $\left(T_{h}-T\right)$, an important assumption underlying the derivation of the model. A systematic analysis of the model parameters derived by fitting to published TTT data indicates that the kinetics of bainite formation is mainly governed by the composition dependence of $Q_{b}$ and $T_{h}$. In addition, the transformation is also influenced by the parameters $d_{\mathrm{eff}}$ and $\lambda$, which are determined by the properties of the austenitic matrix. An empirical formula for $Q_{b}$ is developed that can be of practical use to determine the shape of start curves. Subsequently, the bainite kinetics can be predicted at all temperature levels using the unique relationship between $B$ and $Q_{b}$, provided the model can be tested against one precise experimental data point in the TTT diagram to derive $d_{\text {eff }}$. 


\section{ACKNOWLEDGMENTS}

The author is deeply grateful to Jilt Sietsma (Department of Materials Science and Engineering, Delft University of Technology, Delft, The Netherlands) for all the helpful comments and discussions related to the subject of this manuscript.

\section{OPEN ACCESS}

This article is distributed under the terms of the Creative Commons Attribution Noncommercial License which permits any noncommercial use, distribution, and reproduction in any medium, provided the original author(s) and source are credited.

\section{ELECTRONIC SUPPLEMENTARY MATERIAL}

The online version of this article (doi:10.1007/s11661009-0106-9) contains supplementary material, which is available to authorized users.

\section{REFERENCES}

1. Supplement to the USS Atlas of Isothermal Transformation Diagrams, U.S. Steel Company, Pittsburgh, PA, 1953.

2. Atlas zur warmebehandlung der Stahle, Teil II, Verlag Stahleisen MBH, Dusseldorf, Germany, 1954.

3. Atlas of Isothermal Transformation Diagrams of B.S. En Steels, The Iron and Steel Institute, 1956.

4. Atlas of Isothermal and Cooling Transformation Diagrams, ASM, Metals Park, OH, 1968.

5. Atlas of Time Temperature Diagrams for Irons and Steels, ASM INTERNATIONAL, Materials Park, OH, 1991.

6. H.K.D.H. Bhadeshia: Met. Sci., 1982, vol. 16, pp. 159-66.

7. J. Lee and H.K.D.H. Bhadeshia: Mater. Sci. Eng., A, 1993, vol. 171, pp. 223-30
8. H.I. Aaronson, W.T. Reynolds, G.J. Shiflet, and G. Spanos: Metall. Trans. A, 1990, vol. 21A, pp. 1343-80.

9. H.K.D.H. Bhadeshia: Bainite in Steels, The Institute of Materials, London, 2001

10. A. Borgenstam, M. Hillert, and J. Agren: Acta Mater., 2009, vol. 57 , pp. $3242-52$.

11. F.G. Caballero, C. Garcia-Mateo, M.J. Santofimia, M.K. Miller, and C.G. de Andres: Acta Mater., 2009, vol. 57, pp. 8-17.

12. D. Quidort and Y.J.M. Brechet: ISIJ Int., 2002, vol. 42, pp. 101017.

13. G.I. Rees and H.K.D.H. Bhadeshia: Mater. Sci. Technol., 1992, vol. 8, pp. 985-93.

14. S.M.C. Van Bohemen and J. Sietsma: Int. J. Mater. Res., 2008, vol. 7, pp. 739-47.

15. S.M.C. Van Bohemen and J. Sietsma: New Developments in Metallurgical Applications of High Strength Steels, Buenos Aires, 2008, pp. 1069-83.

16. S.R. Pati and M. Cohen: Acta Metall., 1969, vol. 17, pp. 189-99.

17. C.L. Magee: Phase Transformations, ASM, Metals Park, OH, 1970, pp. $115-68$

18. N.A. Chester and H.K.D.H. Bhadeshia: J. Phys., 1997, vol. 7, pp. 41-46.

19. H.K.D.H. Bhadeshia: Met. Sci., 1981, vol. 15, pp. 175-77.

20. D.P. Koistinen and R.E. Marburger: Acta Metall., 1959, vol. 7, pp. 59-60.

21. S.M.C. Van Bohemen and J. Sietsma: Metall. Mater. Trans. A, 2009, vol. 40A, pp. 1059-68.

22. S.M.C. Van Bohemen and J. Sietsma: Mater. Sci. Technol., 2009, vol. 25 , pp. 1009-12.

23. G.B. Olson and M. Cohen: Metall. Trans. A, 1976, vol. 7A, pp. 1915-23.

24. N. Luzginova: Microstructure and Transformation Kinetics in Bainitic Steels, Delft University of Technology, Delft, The Netherlands, 2008, pp. 67-70.

25. E.S. Davenport and E.C. Bain: Trans. AIME, 1930, vol. 90, pp. $117-31$

26. E.P. Klier and T. Lyman: Trans. AIME, 1944, vol. 158, pp. 394- 422.

27. W. Steven and A.G. Haynes: J. Iron Steel Inst., 1956, vol. 183, pp. $349-59$.

28. Y. Ohmori, H. Ohtani, and T. Kunitake: Trans. ISIJ, 1971, vol. 11 , pp. $250-59$.

29. B. Josefsson and H.O. Andren: J. Phys., 1988, vol. 49 (C6), pp. 293-99.

30. M.X. Zhang and P.M. Kelly: Scripta Mater., 2002, vol. 47, pp. $749-55$.

31. F.G. Caballero and H.K.D.H. Bhadeshia: Curr. Opin. Solid State Mater. Sci., 2004, vol. 8, pp. 251-57. 